Paula Pulgar Alves

Vilniaus universitetas

ppulgaralves@gmail.com

\title{
Reír o no reír: estímulos, problemas y malentendidos a partir del humor en la clase de ELE
}

\begin{abstract}
Resumen:
El uso del humor como estrategia didáctica en clase de ELE ha aumentado en los últimos tiempos. El humor se ve como una fórmula para que los alumnos interioricen no solo conocimientos gramaticales, sino también culturales o pragmáticos. Los estudios sobre la idoneidad de este recurso en clase son variados, pero casi todos coinciden en su importancia. Tras el análisis inicial, el objetivo principal de este artículo es el de exponer y estudiar las experiencias concretas de aula llevadas a cabo con alumnos de español de la Universidad de Vilnius.
\end{abstract}

Palabras clave: humor, didáctica, enseñanza ELE, experiencias de aula, Vilnius

\begin{abstract}
:
To Laugh or Not to Laugh: Stimuli, Problems and Misunderstandings Related to Humor in the SFL Classroom

The use of humor as a didactic strategy in SFL lessons has increased recently. Humor is seen as a tool for students to understand not only grammar but also cultural or pragmatic knowledge. A variety of studies on the appropriateness of this resource agree on its relevance. After the initial analysis, the main objective of this article is to introduce particular classroom activities carried out with students of Spanish as a foreign language at Vilnius University.
\end{abstract}

Keywords: humor, didactics, SFL teaching, classroom experiences, Vilnius 


\section{Introducción}

En los últimos años se han incrementado los estudios en los que se analiza el humor como instrumento en las clases de ELE. Los distintos trabajos sobre el tema en cuestión han apuntado los beneficios, pero también la problemática, inherentes a la utilización de dicho recurso en las aulas con los estudiantes de español. Esta comunicación tiene como objetivo incidir en el valor estimulante del humor en las clases de ELE desde el prisma que ofrece la contextualización particular en un ámbito sociocultural concreto, esto es, el alumnado de Filología de la Universidad de Vilnius. De este modo, y a partir de experiencias concretas de aula, el objetivo es mostrar una panorámica sobre los retos, problemas y estímulos que ofrece la utilización del humor en clase. En el caso que vamos a plantear, la experiencia docente evidencia cómo los diversos orígenes sociolingüísticos determinan una mayor proximidad o lejanía con el humor estandarizado español, lo que trae consecuencias en el plano del aprendizaje y la motivación.

\section{Humor y risa. Palabras de difícil definición}

Para comenzar con nuestra reflexión nos podemos plantear las siguientes cuestiones, todas ellas de difícil resolución: ¿podemos encontrar una definición universal del humor?¿Qué es la risa?

$\mathrm{Si}$ buscamos en el diccionario de la RAE, encontramos varias acepciones de ambas palabras, ninguna de las cuales nos convence del todo en el ámbito en el que nos disponemos a trabajar. En el caso de palabra humor, la RAE nos ofrece definiciones como: 'genio, índole, condición, especialmente cuando se manifiesta exteriormente'; 'jovialidad, agudeza'; 'buena disposición para hacer algo'; o 'cada uno de los líquidos de un organismo vivo'. En cuanto a la palabra risa, las dos primeras acepciones que encontramos tienen sobre todo que ver con elementos de tipo más físico que emocional o mental: 'movimiento de la boca y otras partes del rostro, que demuestra alegría'; o 'voz o sonido que acompaña a la risa'. 
Ninguna de las definiciones anteriores nos parece adecuada para referirnos al asunto que nos ocupa, por lo que vamos a tomar la definición de risa dada por Eduardo Jáuregui (2008: 47). Así pues, según este autor, la risa sería "el mecanismo común a todas las culturas e individuos que responde al humor" (Jáuregui, 2008: 47). El mismo autor manifiesta la dificultad de la definición de ambos términos:

En castellano no existe una palabra de uso cotidiano que identifique este fenómeno emocional sin ambigüedades, dado que «risa» indica también, e incluso principalmente, la expresión de la emoción: los sonidos y gestos que la acompañan. Podríamos emplear la palabra «hilaridad» (pero a mí me parece un tanto forzada), «diversión» (pero esta tiene otras connotaciones que van más allá del humor) o «humor» (que también tiene múltiples significados) (Jáuregui, 2008: 51-52).

Así pues, partimos de la premisa de que es difícil definir ambas palabras sin caer en ambigüedades. Vemos que el humor y la risa suelen aparecer ligadas a otras palabras como diversión, hilaridad o gracia, desde luego, palabras interesantes y conceptos motivadores si estamos hablando de enseñar una lengua extranjera, en el caso que nos ocupa, el español.

Tras mostrar algunas opciones alternativas a la RAE para la definición de los conceptos de humor y risa, nos planteamos las siguientes cuestiones: ¿es el humor algo universal? ¿Existe algo común que nos hacer reír a todos? ¿Se puede traducir el humor?

En cuanto a la primera cuestión, Jáuregui responde afirmativamente. Según sus palabras, "sí existe un elemento común a las diversas tipologías y géneros humorísticos, o al menos una serie de causas universales" (Jáuregui, 2008: 54). Sostiene el autor que "el mismo tipo de eventos que en la sociedad occidental se consideran «graciosos», también hacen reír en las culturas más dispares, y en todas las épocas conocidas" (Jáuregui, 2008: 54). Para el mismo autor, "los estudios etnográficos del humor revelan que las historias cómicas tradicionales se basan en las mismas pretensiones infladas y las mismas caídas en el ridículo que pueden encontrarse en las comedias de Cervantes, 
Molière, Shakespeare, Boccaccio o incluso Santiago Segura" (Jáuregui, 2008: 55).

La presumible universalidad del humor es, probablemente, la que hace que podamos llegar a reírnos de algunos chistes de los Monty Python y a la vez sonriamos ante las viñetas de Maitena. Pero lo cierto es que a veces las cosas no son tan fáciles, y algunas situaciones, chistes o bromas que en un principio a nosotros nos resultan absolutamente graciosos no hacen ni sonreír levemente a personas de otras culturas. Esto es lo que puede suceder en ocasiones con algunos intentos infructuosos de ofrecer a nuestros alumnos momentos de humor español. Luego entraremos más en detalle.

El mismo autor, Jáuregui (2008), considera que, a pesar de la universalidad del humor, también podemos hablar de un humor "particular" o "individual", adscrito a un país o grupo social determinado. Para Pedro J. Alonso García el humor tendría que ver con lo social. Señala el autor que "los criterios para considerar una burla más o menos cruel o ingeniosa varían no solo según los individuos sino también según las sociedades" (Alonso García, 2005: 125). La afirmación de Alonso García podría ejemplificarse en la propia sociedad española. Es sabido por todos que hasta bien entrados los años 80 (puede que incluso los 90), en España eran abundantes las bromas sobre los gais, colectivo que era objeto de burla en sketches de cómicos famosos como Martes y Trece, entre otros. En la actualidad en España el reírse de los gais es algo que se considera políticamente incorrecto y de mal gusto. Estamos hablando de la misma sociedad, pero con una diferencia de unos 30 años.

En cuanto a la tercera cuestión- ¿es traducible el sentido del humor?-, resulta reveladora la anécdota mencionada por Sandri (2013) en su artículo "El humor en cada país", a propósito de lo ocurrido a Reagan en uno de sus viajes a Japón. Parece ser que el por aquel entonces presidente fue a dar una charla y en su intervención contó un chiste. Tras la rápida mediación del traductor el público nipón estalló en risas. Después del evento Reagan preguntó al intérprete que cómo había logrado una traducción tan rápida y tan bien recibida por el 
público. Este le contestó a Reagan que simplemente había dicho a los asistentes que el presidente había contado un chiste.

Aquí tenemos solo un ejemplo más de lo difícil que puede ser en ocasiones traducir algunas bromas, sobre todo cuando tienen que ver con el significado o los dobles sentidos de las palabras, pero es indudable que constituyen un interesante recurso para trabajar en las clases de español.

\section{Breves apuntes sobre el humor en clase de ELE}

En los últimos años, como ya hemos señalado, han aumentado los estudios sobre el humor en clase de ELE, pero no solo en esta rama de la educación es el humor y la risa una herramienta efectiva. En este sentido resulta revelador un estudio de Mónica Guitart (2007) en el que se analiza el uso del humor y la broma en clases en principio tan serias como las de Estadística en una Facultad de Ingeniería. Como muestra el estudio, el humor es un recurso jugoso para cualquier tipo de enseñanza. Desde luego es algo imprescindible en clases de ELE donde varios aspectos de la cultura y de la lengua pueden ser mostrados desde la perspectiva de la risa y la broma. Según Alonso García,"A través del humor se hacen más visibles y comprensibles aspectos o realidades tan importantes en el aprendizaje de una lengua como la pragmática, la (inter)cultura, el español coloquial, la entonación y la creatividad" (Alonso García, 2005: 124). Para el mismo autor, el humor es "como una lente de gran aumento a través de la cual se perciben parámetros de comportamiento" (ibidem: 128). En este sentido resulta interesante utilizar diálogos y escenas de tipo humorístico en los cuales aparezcan aumentados aspectos característicos de la cultura y la lengua que se están aprendiendo. Diego Ojeda Álvarez y Olga Cruz Moya (2004) hablan, precisamente, de la utilidad del humor en clase de ELE debido básicamente al predominio de lo dialógico en las escenas de tipo humorístico, por la abundancia de juegos de palabras, de la polisemia y de los coloquialismos, entre otros recursos. Consideran los mismos autores que "la comunicación lúdica — en general—y los chistes —en particular - son fuentes de información lingüística a todos los niveles: 
fónico, léxico, morfosintáctico y, especialmente, pragmático" (Ojeda, Moya, 2004: 239).

Por su parte, autores como Ricard Morant (2006), se preguntan si con humor se puede aprender mejor una lengua. El autor argumenta que es precisamente gracias al humor como mejor se explican determinados elementos de la lengua que normalmente se consideran tabúes. Así pues, según este autor, la risa y la comedia hacen que se destabuicen términos de la lengua que de otra manera, sobre todo para determinadas personas, serían incómodos de explicar.

Como podemos ver, para todos estos autores el humor puede ser aprovechado en múltiples ámbitos del aprendizaje de la lengua. Con el humor rompemos tabúes, enseñamos el comportamiento de los hablantes, aprendemos palabras coloquiales o practicamos la pronunciación. El humor se nos presenta de esta manera como una forma atractiva de abordar determinados conocimientos. Pero hay otra cuestión que debemos plantearnos: ¿son todas las culturas igual de permeables al uso del humor en el aula de ELE? ¿Son siempre bien recibidas las bromas en clase?

Estas preguntas trataremos de resolverlas a continuación.

\section{Puesta en práctica en el aula: experiencias concretas y reac- ciones del alumnado de ELE en la Universidad de Vilnius}

Nos disponemos ahora a analizar las experiencias propias en relación con el tema del humor en las clases de español comunicativo de la Universidad de Vilnius. En primer lugar conviene señalar que Vilnius, capital de Lituania, es una ciudad que ofrece un complejo entramado sociolingüístico en el que conviven estudiantes mayoritariamente nacidos en el país, pero con procedencias culturales e idiomáticas muy diversas, entre las que priman los orígenes lituanos, polacos, rusos y bielorrusos. Según datos del año 2008, en Lituania el $80 \%$ de la población es lituana, el 7\% polaca, el $6 \%$ rusa y el 1,2\% bielorrusa. En cuanto a la capital, Vilnius, tiene un 58\% de lituanos, un $19 \%$ de polacos, un 14\% de rusos y un 4\% de bielorrusos (Everatt, 2008: 243). Esta variedad cultural e idiomática se refleja en las clases de español, donde 
los alumnos tienen distintos problemas de aprendizaje según cual sea su lengua materna y responden de distinta manera a los estímulos del aula. Al trabajar el tema del humor y la risa, la diversidad de nuestros alumnos se hace patente y nos ofrece algunos momentos interesantes desde el punto de vista cultural y sociolingüístico, dada la variedad de reacciones ante un mismo estímulo. Pongamos como ejemplo de esto una experiencia de clase llevada a cabo con varios grupos de cuarto curso del Grado combinado de Filología Lituana y Española.

A los alumnos, en su mayoría mujeres (98\%), con un nivel aproximado de B2-C1, se les propuso una actividad para trabajar el lenguaje coloquial. Dicho ejercicio estaba basado en la propuesta de Agustina Menini titulada "El amor en televisión" (el desarrollo de la actividad de Menini se puede descargar del portal Todoele.net). La actividad consistía en la visualización de un sketch de José Mota en el que se hacía una parodia del famoso programa televisivo Mujeres, hombres $y$ viceversa. Además del visionado del vídeo del popular cómico español, la creadora de la actividad proponía también ver algunas escenas del famoso programa de Tele 5. En nuestro caso, los alumnos vieron el sketch de Mota y después analizaron una entrevista hecha en televisión a los protagonistas masculinos del susodicho programa. Los resultados de la actividad fueron, cuanto menos, curiosos.

Por un lado, ante el chiste final de la parodia de Mota, en dos de las tres clases solo estallaron en carcajadas los alumnos de procedencia polaca. Los alumnos rusos sonrieron y, curiosamente, los lituanos le encontraron menos gracia. Al preguntar a los alumnos lituanos qué les había parecido el vídeo, algunos opinaban que el humor de Mota parecía "zafio" y "vulgar"; por contrapartida, a los alumnos polacos y rusos les había parecido bastante gracioso.

Por otra parte, tras ver la entrevista de los chicos de Mujeres, hombres y viceversa, alumnas y alumnos de toda procedencia pensaron que los chicos estaban también llevando a cabo una parodia. En este caso la broma y la realidad se cruzaron de manera interesante.

Tras la actividad anterior los alumnos tuvieron que explicar qué les parecía el humor español y a continuación escribir como trabajo de casa una redacción titulada “¿De qué se ríen los lituanos?”. 
Ante la primera cuestión, a los alumnos lituanos les pareció que el humor español reflejado en el vídeo de Mota, era, como ya hemos dicho, bastante vulgar. Hablando en general, consideraban que el humor español era más similar al ruso o incluso al polaco y les parecía poco correcto el uso de palabras malsonantes y "ofensivas". Hay que señalar en este sentido que el idioma lituano se caracteriza, en general, por la falta de palabras malsonantes. De hecho, estas en su mayoría no proceden del lituano, sino que son préstamos de otras lenguas (principalmente del ruso).

En cuanto al segundo punto, los alumnos escribieron interesantes redacciones en las que hablaban sobre el humor y la risa en su país. Los textos de alumnos de procedencia lituana recogían afirmaciones críticas del tipo "Desafortunadamente, el pobre y banal sentido del humor es dominante" (en Lituania). Por su parte, los alumnos de procedencia rusa escribieron comentarios como "Respecto al humor en Lituania, pienso que no es tan popular y tan bueno como en otros países, por ejemplo, en Rusia o España". Tanto los alumnos rusos como los polacos consideraban que el humor de su comunidad era mejor. Incluso alguna alumna recogió en su redacción la siguiente afirmación: "Los lituanos en general parecen muy serios y de mal humor todo el tiempo". Sin embargo, no todo fueron críticas hacia el humor de los lituanos. La mayoría de lituanos consideraba que ellos también tenían sus chistes y bromas, aunque admitían que muchas veces eran difíciles de entender para una persona de otra nacionalidad. También señalaban que el humor negro era un tema dominante en los chistes del país y que algunas cuestiones seguían hoy día siendo tabú (esto lo atribuían al conservadurismo de la sociedad de su país). Por otra parte, en cuanto a los tópicos y estereotipos, los lituanos comentaban que en su país (al igual que en otros) había muchos chistes sobre chicas rubias, suegras, polacos, rusos y judíos. De igual modo, parece ser que se hacen chistes sobre personajes populares estereotipados. Ponían el ejemplo de Petriukas, figura plana, característica de los chistes del país (parecida al Jaimito español), o de Chuck Norris, curiosamente este último también generador de bromas varias en otros países, entre ellos España. 
Finalmente, para terminar el tema se les preguntó a los alumnos qué opinaban del uso del humor y de la risa en las clases de español. Los alumnos que contestaron a la pregunta dijeron que les parecía bien, pero que les resultaba raro, ya que los profesores lituanos no solían hacer bromas en clase. Una de las estudiantes puso un interesante ejemplo en relación con lo anterior, al señalar que había asistido a una charla de un profesor lituano que vivía desde hacía décadas en EE. UU, y que se había quedado muy sorprendida al comprobar cómo el conferenciante comenzaba la charla haciendo una serie de bromas.

\section{Conclusiones}

Tras analizar los distintos datos de las actividades propuestas en nuestras clases de español llegamos a conclusiones de distinto tipo. Por un lado parece que el uso del humor en el aula puede ser una buena herramienta de comunicación y de enseñanza siempre que tengamos en cuenta que en algunas ocasiones las personas de otros países o culturas pueden llegar a sentirse incómodas ante determinadas situaciones planteadas o incluso ante el uso de ciertas palabras o expresiones (por ejemplo, según nuestra experiencia, como ya hemos señalado, a algunos alumnos lituanos les resulta violento que el profesor haga referencia a palabras "malsonantes" o "vulgares").

Por otra parte,durante las actividades planteadas en nuestras clases constatamos la innegable universalidad del humor, pero también comprobamos que los mismos estímulos humorísticos no siempre producen idénticos efectos (en forma de risa) en personas de distintas culturas o países. En nuestro caso, en general, las reacciones ante los estímulos humorísticos dependieron bastante de la procedencia cultural de nuestros alumnos. Se hacen aquí evidentes las palabras de Jáuregui: "Es evidente que el carácter específico de los estímulos humorísticos varía tan radicalmente como la cultura misma" (Jáuregui, 2008: 58). 


\section{Bibliografía}

ALONSO GARCÍA, P. J. (2005), "Riendo se entiende la gente. El humor en la clase de ELE”, en: Álvarez, A., [et al.] (eds.), La competencia pragmática y la enseñanza del español como lengua extranjera. Actas del XVI Congreso Internacional de ASELE, Oviedo 22-25 de septiembre de 2005, ASELE, Oviedo, pp. 124-132.

EVERATT, J. (2008), Vilnius. A Complete Guide, Baltos Lankos Publishers, Vilnius.

GUITART-CORIA, M. B. (2007), Permitido reir ... estamos en clase. El humor como recurso metodológico en el aula de estadística, [proyecto de tesis doctoral], Universidad de Mendoza.

JÁUREGUI, E. (2008), "Universalidad y variabilidad cultural de la risa y el humor”, AIBR. Revista de Antropología Iberoamericana, 3(1), Madrid, pp. 46-63.

MENINI, A. (2015), El amor en televisión, [on-line] http://www.todoele.net/actividades/Actividad_maint.asp? ActividadesPage $=4 \&$ Actividad_id $=585,16.04 .2015$.

MORANT, R. (2006), “¿Con humor se explica y se aprende una lengua mejor?”, Pragmalingüística, 14, Cádiz, pp. 87-99.

OJEDA ÁLVAREZ, D., CRUZ MOYA, O. (2004), "«Yo me parto». Oralidad, humor, gramática y pragmática, un cóctel lúdico para el aula de ELE", en: Castillo Carballo, M. A., [et al.] (coords.), Las Gramáticas y los Diccionarios en la Enseñanza del Español como Segunda Lengua. Deseo y Realidad. Actas del XV Congreso Internacional de ASELE, Sevilla 22-25 de septiembre de 2004, Sevilla, pp. 234-240.

SANDRI, P. M. (2013), "El humor según cada país", [on-line] http://www. lavanguardia.com/estilos-de-vida/20130816/54379403091/el-humor-segun-cada-pais.htmlforej, 16.08.2013. 